\title{
Effect of teaching program on nurses' performance about hypoalbuminemia after liver transplantation.
}

\author{
Asmahan S. Mohamed ${ }^{1}$, Mona A. Mohamed ${ }^{2}$ \& Amal E. Abdel Hafez ${ }^{3}$. \\ 1. Specialist of nursing at Alrajhy liver hospital, Assuit University, Egypt. \\ 2. Assistant professor of critical care and emergency nursing, faculty of Nursing, Assuit University, Egypt. \\ 3. Lecture of critical care and emergency nursing, faculty of nursing, Assuit University, Egypt.
}

\begin{abstract}
Hypoalbuminemia is a common health problem among liver transplant patients. Moreover, it is documented that $20 \%$ of liver transplant patients have hypoalbuminemia at admission. Aim of study: To evaluate the effect of teaching program on nurses' performance about hypoalbuminemia after liver transplantation. Research design: A quasi experimental (pre/post test). Subject and Methods of this study was consisted of 30 nurses' care for hypoalbuminemic patients after liver transplantation. Two Tools were used for data collection. Tool I pre/post nurses' knowledge assessment questionnaire. Tool II pre/post observational checklist. Results: The study explained that the majority of nurses had poor knowledge and practice related to hypoalbuminemia after liver transplantation before teaching program, which has been improved after teaching program significantly $(\mathrm{P}=0.000)$, a positive correlation was found between knowledge and practice scores of the study subjects significantly $(\mathrm{P}=0.000)$. In Conclusion, teaching is important to clarify, remind, and master nurses' knowledge and practice would have a positive impact upon their knowledge and practice. The study Recommended that continuous In-service training programs for the purpose of updating the knowledge and practice about hypoalbuminemia after liver transplantation for nurses.
\end{abstract}

\section{Keywords: Hypoalbuminemia, Knowledge, Liver Transplantation, Performance \& Teaching Program.}

\section{Introduction}

Hypoalbuminemia, associated with liver transplant patient typically defined as serum albumin concentration less than $3.0 \mathrm{~g} / \mathrm{dL}(30 \mathrm{~g} / \mathrm{L})$, there is significant interest in identifying, assessing, and treating hypoalbuminemia after liver transplantation because it has clearly been established as a marker for disease severity and is associated with poor outcomes. (Jewell, 2017).

The most common characteristics of hypoalbuminemia after liver transplantation are edema in legs or face, skin that's rougher or drier than normal, hair thinning, difficulty breathing, feeling weak or exhausted, irregular heartbeat, abnormal weight gain, loss of appetite, diarrhea , feeling nauseous and vomiting, The symptoms depend on what's causing the condition. (Peralta, 2017).

The main role of professional nurse is the assessment, implementation, continuous monitoring and evaluation of hypoalbuminemic patients after liver transplantation. The nursing staffs are in need for applying this teaching program to improve the standard of patient care. The teaching program is considered to be an important means to provide nurses with theoretical and technical information need to acquire knowledge and practice necessary to continually improve nursing practice about patient with hypoalbuminemia after liver transplantation. (Fullwood, 2011).
Nurses are the health team members who spend most time with hypoalbuminemic patient after liver transplantation, giving them care and an essential role as educators in the different learning needs and demands. Therefore, these professionals' scientific background is relevant with a view to putting in practice effective strategies to promote changes in hypoalbuminemic patients' health. Patients with hypoalbuminemia after liver transplantation need nursing interventions to support the required health changes, so as to prevent and control hypoalbuminemia after liver transplantation progress. Teaching program was focused on promoting the development of nurses' knowledge and practice for management of hypoalbuminemia after liver transplantation. (Karaahmet, 2014).

\section{Significance of the study}

Hypoalbuminemia is the common complication and the key of prognosis after liver transplantation in which nurses need to know all aspect of care to improve patient health.

Because of hypoalbuminmia in patients with endstage liver disease persists for weeks even after liver transplantation. The nurse there fore, needs to become more skillful and knowledgeable to introduce care for the patients.

Teaching program is very important for the nurses to increase knowledge and practice about assessment of hypoalbuminemia, to help them to assess patient 
status and when to inform doctor to manage any complication.

\section{The Aim of Study}

The present study aim to identify the effect of teaching program on nurses' performance about hypoalbuminemia after liver transplantation.

\section{Research Hypotheses}

1. The mean knowledge scores of the study nurses will be improving post the implementation of the teaching program about hypoalbuminemia after liver transplantation.

2. The mean practice scores of the study nurses will be improving post the implementation of the teaching program about hypoalbuminemia after liver transplantation.

3. A positive relation will exist between knowledge and practice score obtained by nurses receiving teaching program.

\section{Subject \& Methods \\ Research design}

A quasi experimental research design (pre/post test) was utilized this study.

Study variables: The independent variable was the teaching program. While the dependent variable was nurses' knowledge and practice.

\section{Setting}

The study was done in Intensive Care Unit at Alrajhy liver hospital at Assuit university hospital. This Intensive Care Unit consist of six beds and approximately thirty nurses who are providing direct patient care and willing to participate in this study.

\section{Subject}

The study was include a convenience sampling of all available nurses $(n=30)$ working in Intensive Care Unit at Alrajhy liver hospital.

Tools for data collection

Two tools were used in this study:

Tool (1) (Nurses structure interviewer questionnaire): This tool was developed by researcher to assess bio-demographic data and nurses' knowledge included in the study. It developed by the researcher based on literature review. (Dultz, 2017 \& Brodovicz, 2010). It was constructed based on the following parts:

Part one: It included bio-demographic data of the nurses as ( age, sex, level of education, experience, and previous training).

- Part two: This part included pre/ post Nurses' knowledge questionnaire about anatomy and physiology of the liver, 'assessment of hypoalbuminemia ( post-operative care of patient with hypoalbuminemia after liver transplantation, assess of nutritional status ,serum albumin monitoring, assessing edema, monitor of fluid chart) .It consist of forty multiple choice and true /false questions covering five main parts.

- Basic knowledge about anatomy and physiology of the liver which included seven (7) questions.

- Knowledge about hypoalbuminemia post liver transplantation which included twelve questions.

- Human albumin and nursing care during human albumin administration which included eight (8) questions.

- Edema and nursing care for edema which included six (6) questions.

- Assess of nutritional status and urine output which included seven (7) questions.

Scoring system: Total question were (40) questions: (17) questions of them were multiple choice items had three alternative answers. And (23) questions of them were true/false questions. A score value of (1) was awarded to each correct answer and (zero) was allotted for wrong answer. The total score of nurses' knowledge was calculated and classified as follows: $\geq 75 \%$ was considered good, 60-<75 \%was considered fair. And less than $<60 \%$ was considered poor.

Tool (2) :( Nurses' pre/post practice observational checklists tool): It was developed by the researcher after reviewing the related literature (Hogan, 2014, \& Cheng, 2013). The tool covered all the steps procedure of nursing care of patient with hypoalbuminemia after liver transplantation. The observational check list comprised of 40 steps as follow:

- Nutritional Status assessment which included fifteen (15) steps.

- Measuring edema which included eight (8) steps.

- Free albumin procedure which included eleven (11) steps.

- Fluid chart which included six (6) steps

Scoring system: The total score for all steps were 80 and every step was evaluated as follows: correctly done was scored (2), in-correctly done was scored (1), and not done was scored (0). The total score of nurses' skills was calculated and classified as follows: $\geq 75 \%$ was considered good, $60-<75 \%$ was considered fair. And less than $<60 \%$ was considered poor.

Construction of teaching program

The teaching program was developed by the researcher based on the previous assessment of nurses' knowledge and performance. Available resources and review of relevant literature.

General objective of the program

The overall objective of the developed teaching programs to improve the critical care nurses' knowledge and performance about hypoalbuminemia after liver transplantation. 


\section{Specific objective of the program}

By the end of the program the nurses were able to: Identify the anatomy and physiology of the liver, define liver transplantation, list the indication and contraindication of liver transplantation, apply nursing care of patient with hypoalbuminemia post liver transplantation, define hypoalbuminemia, list Causes and Symptoms of hypoalbuminemia. identify liver function test, identify serum albumin value, list indication and contraindication of human albumin, recognize nursing implication of human albumin, identify edema and list edema grading, identify nursing management of edema, calculate urine output, and assess nutritional status.

\section{Methods}

The study was conducted on three phases (preparatory phase, implementation phase and evaluation phase).

\section{preparatory phase}

-permission to conduct the study was obtained from the hospital responsible authorities after explanation of the aim of the study.

Tools develop: Tool one used in this study was developed in Arabic by the researcher based on reviewing the relevant literature.

-Content validity and reliability: The tools were tested for content related validity by jury of 2 specialists in the field of critical care nursing, and the necessary modifications were done regarding Arabic translation of questions. The reliability was test for tool one and tool two by using Cronbach's coaefficient alpha $(\mathrm{r}=0.837,0.793$ respectively) which is acceptable.

-permission for voluntary participation was obtained from nurses after the purpose of the study was explained.

-An approval was obtained from the local ethical committee and the study was followed the common ethical principles in clinical research.

Ethical consideration: Research proposal was approved from ethical committee in the faculty of nursing Assuit University. There is no risk for study subject during application of research. The study follows common ethical principle in clinical research. Informed consent was reserved from participating person post explaining the purpose of study. Patient was assured that the data of this research wasn't refused without second permission. Confidentiality and anonymity were assured. The study subject privacy was considered during collection of data.

A pilot study: Done into (10\%) nurses to test the feasibility and applicability of the tool and the necessary modification was done. and this study didn't added to the total number of nurses in the study

\section{Development of the teaching program}

The teaching program was developed by the researcher, after reviewing the relevant literature. The following steps were adopted to develop the program. $\square \square$ Stating the program general and specific objectives.

$\square \square$ Planning the program: the content of the program were arranged into three teaching sessions, every session take about 30 minute in addition to preliminary one. The content of the program covered two parts related to:

$\square \square$ Knowledge about hypoalbuminemia after liver transplantation.

$\square \square$ practice required for hypoalbuminemia after liver transplantation

\section{Learning environment}

The program was conducted as session in official job duty by. Lectures and discussion by using audiovisual aids (PowerPoint presentation and booklet) which developed in Arabic by the researcher base on reviewing the related literature. Demonstration and re-demonstration: The researcher conducting demonstration using teaching materials (photos, video and application on the patient).

\section{Arranging the subgroup:}

- The total sample was divided into six subgroups included five nurses each session for better practice and understanding.

implementation phase and evaluation phase

- All nurses were interviewed during break time (one hour) in different shifts or before beginning of shift. - Assessment of knowledge was done as follows:

$\square \square$ At beginning of study was considered as pre-test assessment and as base line data for latter comparison with future post-test.

- Assess nurses' practice:

$\square \square$ The researcher observes the nurses' practice using observational checklist by tool two before program implementation.

\section{Implementation of program}

The program was implemented for the six subgroups of nurses. All groups were exposed to three sessions in addition to the preliminary one.

Preliminary session: In this session the researcher met the participant and explained the objectives, contents, methods of evaluation of program, Anatomy and physiology of liver.

Session I included: Definition of liver transplantation, indication, contraindication and nursing care post liver transplantation.

Session II included: Definition of hypoalbuminemia, causes and Symptoms of hypoalbuminemia.

Session III included: Liver function test, indication, contraindication and nursing implication of human albumin, assessing edema, grading and nursing management of edema, urine output and asses 
nutritional status. Group discussion was encouraged with continuous feedback to ensure understanding and achievement of the specific objective of the program. An open channel of communication was established between the researcher and nurses to answer any question and reinforce the gained information and correct actions. In the last session the researcher summarized and emphasized the important points. And each nurse demonstrates and re-demonstrates the steps individually and completely performed the steps.

\section{Evaluation of teaching program}

The nurses' knowledge and practice were evaluated again after (4) weeks of implementing the teaching program using the same pre-test study tools that used before. The evaluation took approximately months and the data collection process of the research took (7) months starting from June 2017to December 2017.

Statistical analysis

- The data entry and data analysis were done using (SPSS Ver.23.).

- Descriptive statistics (number, percentage, mean and standard deviation) were done.

- Chi-square test was done to compare qualitative variables between before and after group.

- Independent sample t-test was done to compare quantitative variables between before and after group.

- P-value considered statistically significant when $\mathrm{p}<0.05$.

\section{Result}

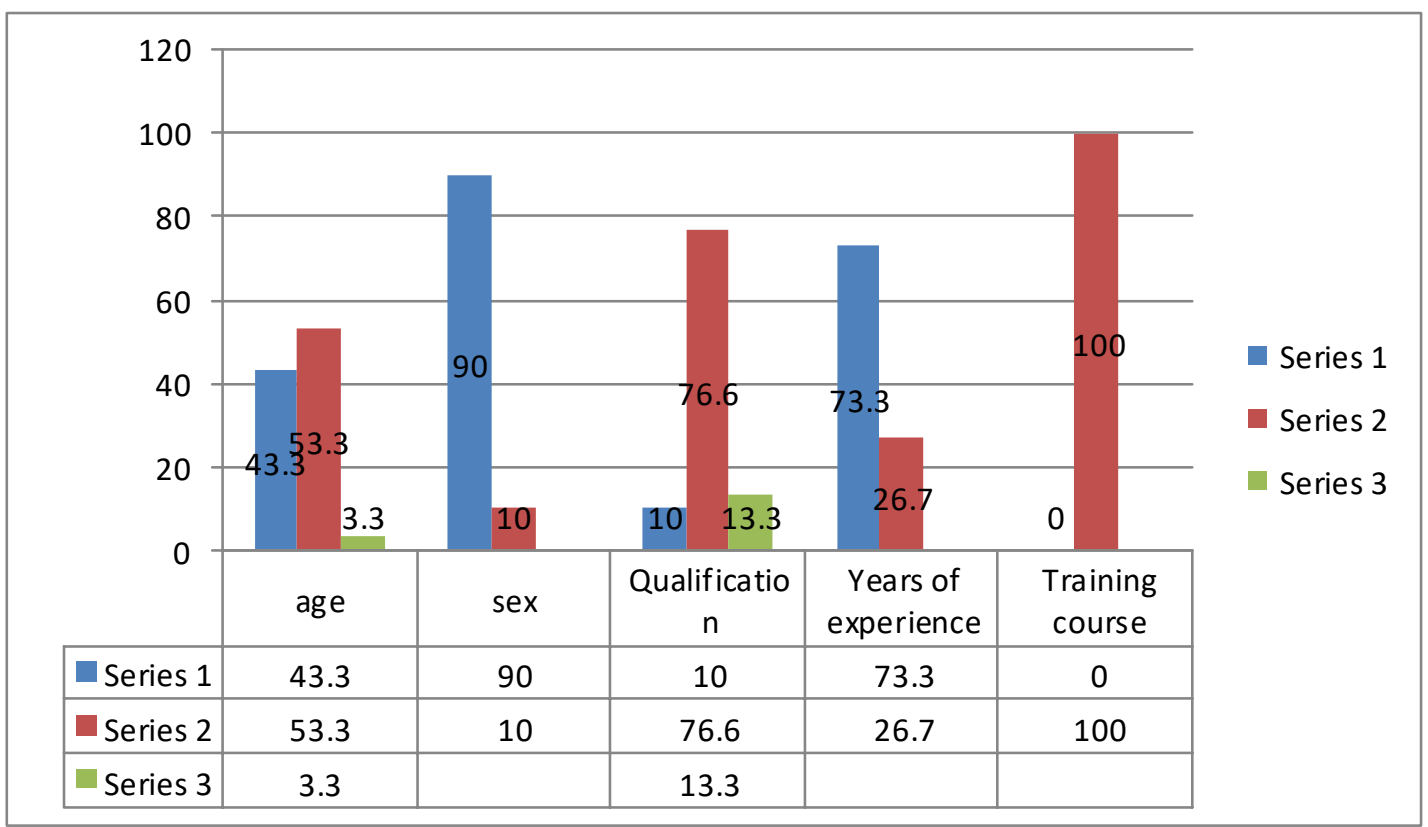

Figure (I): Frequency distribution of nurse`s bio-demographic features of the studied nurses $(n=30)$.

Section II:The testing of research hypotheses I

Table (1): Percentage distribution of nurses' knowledge about anatomy and physiology of liver before and after teaching program $(n=30)$.

\begin{tabular}{|c|c|c|c|c|c|}
\hline \multirow{2}{*}{$\begin{array}{l}\text { Nurses' knowledge about anatomy } \\
\text { and physiology of liver }\end{array}$} & \multicolumn{2}{|c|}{$\begin{array}{l}\text { Pre test } \\
(\mathrm{n}=30)\end{array}$} & \multicolumn{2}{|c|}{$\begin{array}{l}\text { Post test } \\
(n=30)\end{array}$} & \multirow[t]{2}{*}{ p-value } \\
\hline & No. & $\%$ & No. & $\%$ & \\
\hline Lobes of the liver. & 17 & 56.6 & 28 & 83.3 & $0.001 *$ \\
\hline Location of the liver. & 20 & 66.7 & 29 & 96.7 & $0.003^{*}$ \\
\hline Weight of the liver. & 22 & 73.3 & 29 & 96.7 & $0.009 *$ \\
\hline Function of the liver. & 22 & 73.3 & 28 & 93.3 & $0.009 *$ \\
\hline Physiology of the liver. & 18 & 60.0 & 26 & 86.7 & $0.000^{*}$ \\
\hline
\end{tabular}

*statistically significant difference $(p<0.05)$ 
Table (2): percentage distribution of nurse`s knowledge about Hypoalbuminemia post liver transplantation before and after teaching $\operatorname{program}(n=30)$.

\begin{tabular}{|c|c|c|c|c|c|}
\hline \multirow{2}{*}{ Nurse`s knowledge about Hypoalbuminemia post liver transplantation } & \multicolumn{2}{|c|}{$\begin{array}{c}\text { Pre test } \\
(\mathrm{n}=30)\end{array}$} & \multicolumn{2}{|c|}{$\begin{array}{c}\text { Post test } \\
(n=30)\end{array}$} & \multirow{2}{*}{ p-value } \\
\hline & $\mathbf{n}$ & $\%$ & $\mathbf{n}$ & $\%$ & \\
\hline Definition of hypoalbuminemia. & 15 & $\overline{50.0}$ & 29 & 96.7 & $0.000 *$ \\
\hline Albumin is a major protein in human body. & 10 & 33.3 & 25 & 83.3 & $0.000^{*}$ \\
\hline Albumin making up about $55-60 \%$ of total human plasma protein by mass. & 25 & 83.3 & 28 & 93.3 & 0.529 \\
\hline The causes of hypoalbuminemia. & 28 & 93.3 & 29 & 96.7 & 0.749 \\
\hline Hypoalbuminemia due to un adequate intake of amino acid. & 17 & 56.7 & 28 & 93.3 & $0.001 *$ \\
\hline Signs and symptoms of hypoalbuminemia. & 10 & 33.3 & 27 & 90.0 & $0.000 *$ \\
\hline Peripheral edema considers most appearance symptoms of hypoalbuminemia. & 9 & 30.0 & 29 & 96.7 & $0.000 *$ \\
\hline Definition of liver transplantation. & 20 & 66.7 & 28 & 93.3 & $0.011 *$ \\
\hline Indication of liver transplantation. & 17 & 56.7 & 29 & 96.7 & $0.001 *$ \\
\hline Contraindication of liver transplantation. & 18 & 60.0 & 27 & 90.0 & $0.003 *$ \\
\hline
\end{tabular}

*statistically significant difference $(p<0.05)$

Table (3): The Total score of nurses knowledge categories pre and post implementing of the teaching $\operatorname{program}(\mathbf{n}=\mathbf{3 0})$.

\begin{tabular}{|c|c|c|c|c|c|c|c|c|c|c|c|c|c|}
\hline \multirow{3}{*}{$\begin{array}{l}\text { The Total score of nurses } \\
\text { knowledge categories }\end{array}$} & \multicolumn{4}{|c|}{ Pre test } & \multicolumn{2}{|c|}{$(n=30)$} & \multicolumn{4}{|c|}{ Post test } & \multicolumn{2}{|c|}{$=30)$} & \multirow{3}{*}{$\begin{array}{c}\text { p- } \\
\text { value }\end{array}$} \\
\hline & \multicolumn{2}{|c|}{ Poor } & \multicolumn{2}{|c|}{ Fair } & \multicolumn{2}{|c|}{ Good } & \multicolumn{2}{|c|}{ Poor } & \multicolumn{2}{|c|}{ Fair } & \multicolumn{2}{|c|}{ Good } & \\
\hline & $\mathrm{n}$ & $\%$ & $\mathbf{n}$ & $\%$ & n & $\%$ & $\mathbf{n}$ & $\%$ & $n$ & $\%$ & $\mathbf{n}$ & $\%$ & \\
\hline $\begin{array}{l}\text { Knowledge about anatomy } \\
\text { and function of liver. }\end{array}$ & 6 & 20.0 & 18 & 60.0 & 6 & 20.0 & 0 & 0.0 & 9 & 30.0 & 21 & 70.0 & $0.000 *$ \\
\hline $\begin{array}{l}\text { Knowledge about } \\
\text { Hypoalbuminemia post liver } \\
\text { transplantation. }\end{array}$ & 0 & 0.0 & 4 & 13.3 & 26 & 86.7 & 0 & 0.0 & 1 & 3.3 & 29 & 96.7 & $0.000 *$ \\
\hline $\begin{array}{l}\text { knowledge about serum } \\
\text { albumin and nursing care } \\
\text { during give human albumin }\end{array}$ & 1 & 3.3 & 2 & 6.7 & 27 & 90.0 & 0 & 0.0 & 0 & 0.00 & 30 & 100.0 & $0.000 *$ \\
\hline $\begin{array}{l}\text { knowledge about edema and } \\
\text { nursing care of patient with } \\
\text { edema }\end{array}$ & 20 & 66.7 & 10 & 33.3 & 0 & 00.0 & 1 & 3.3 & 14 & 46.7 & 15 & 50.0 & $0.000 *$ \\
\hline $\begin{array}{l}\text { knowledge about nutritional } \\
\text { status and urine out put }\end{array}$ & 13 & 43.3 & 15 & 50.0 & 2 & 6.7 & 1 & 3.3 & 16 & 53.3 & 13 & 43.3 & $0.000 *$ \\
\hline Total knowledge & 29 & 96.7 & 1 & 3.3 & 0 & 00.0 & 0 & 0.0 & 0 & 00.0 & 30 & 100.0 & $0.000 *$ \\
\hline
\end{tabular}

*statistically significant difference $(p<0.05)$

Section III:The testing of research hypotheses II

Table (4): The total score of nurses' practice categories before and after teaching program $(n=30)$.

\begin{tabular}{|c|c|c|c|c|c|c|c|c|c|c|c|c|c|}
\hline \multirow{3}{*}{$\begin{array}{c}\text { Total score of nurses } \\
\text { practice categories }\end{array}$} & \multicolumn{4}{|c|}{ Pre test } & \multicolumn{2}{|c|}{$(\mathbf{n = 3 0 )}$} & \multicolumn{4}{|c|}{ Post test } & \multicolumn{2}{|c|}{$(n=30)$} & \multirow{3}{*}{$\begin{array}{c}\text { p- } \\
\text { value }\end{array}$} \\
\hline & \multicolumn{2}{|c|}{ Poor } & \multicolumn{2}{|c|}{ Fair } & \multicolumn{2}{|c|}{ Good } & \multicolumn{2}{|c|}{ Poor } & \multicolumn{2}{|c|}{ Fair } & \multicolumn{2}{|c|}{ Good } & \\
\hline & $\mathbf{n}$ & $\%$ & $\mathbf{n}$ & $\%$ & $\mathbf{n}$ & $\%$ & $\mathbf{n}$ & $\%$ & $\mathbf{n}$ & $\%$ & $\mathbf{n}$ & $\%$ & \\
\hline $\begin{array}{l}\text { practice of nutritional } \\
\text { status assessment }\end{array}$ & 30 & 100.0 & 0 & 00.0 & 0 & 00.0 & 0 & 00.0 & 1 & 3.3 & 29 & 96.7 & $0.000^{*}$ \\
\hline $\begin{array}{l}\text { practice of measuring } \\
\text { edema }\end{array}$ & 30 & 100.0 & 0 & 00.0 & 0 & 00.0 & 0 & 00.0 & 2 & 6.7 & 28 & 93.3 & $0.000^{*}$ \\
\hline $\begin{array}{l}\text { practice for free } \\
\text { albumin administration }\end{array}$ & 25 & 83.3 & 4 & 13.3 & 1 & 3.3 & 2 & 6.7 & 4 & 13.3 & 24 & 80.0 & $0.000^{*}$ \\
\hline practice for fluid chart & 30 & 100.0 & 0 & 00.0 & 0 & 00.0 & 3 & 9.7 & 16 & 51.6 & 11 & 38.7 & $0.000^{*}$ \\
\hline Total practice & 29 & 96.7 & 1 & 3.3 & 0 & 00.0 & 0 & 00.0 & 1 & 3.3 & 29 & 96.7 & $0.000^{*}$ \\
\hline
\end{tabular}

*statistically significant difference $(p<0.05)$ 
Section IV: The testing of research hypotheses III

Table (5) the correlation between total score of nurses `knowledge with practice categories before and after teaching program $(n=30)$.

\begin{tabular}{|l|l|c|c|}
\hline \multicolumn{2}{|c|}{ practice } & \multicolumn{2}{c|}{ Total knowledge } \\
\cline { 3 - 4 } \multicolumn{2}{|l|}{ Total practice } & Pre-test & Post-test \\
\cline { 2 - 4 } & p-value & 0.193 & 0.785 \\
\hline
\end{tabular}

$*_{\text {statistically significant difference }(p<0.05)}$

Figure (I): Shows bio-demographic data of studied nurses. It was found that; the near of half of nurses $(53.3 \%)$ their aged ranged from $25->30$ years, $(90.0 \%)$ of them were female. Concerning there qualification $(76.6 \%)$ of the nurses held technician institute of nursing, (13.3\%) of the nurses held Diploma, (10\%) of the nurses held Bachelor of Nursing. Moreover (73.3\%) of them had equal or less than 5 years of experience and $(26.7 \%)$ of them had more than 5 years of experience. In relation to their previous training on hypoalbuminemia, the table reveals that all of nurses not receiving any previous training courses about hypoalbuminemia.

Table (1): Illustrates percentage distribution of nurse`s knowledge about anatomy and physiology of liver before and after teaching program. As regard the lobes, location and weight $(56.6 \%, 66.7 \%$ and $73.3 \%)$ of nurses' answers correctly before teaching program respectively, While the answers of them $(83.3 \%$, 96.7\% and 96.7\%)were correct after teaching program respectively. Furthermore the answers (73.3\% and $60.0 \%$ ) of nurses regarding the function, and the physiology of the liver were correct before teaching program respectively, compared with (93.3\%, and $86.7 \%$ ) were correct after teaching program respectively with statistically significant difference $(\mathrm{P}<0.05)$.

Table (2): Illustrates percentage distribution of nurse`s knowledge about Hypoalbuminemia post liver transplantation before and after teaching program. The answers $(50.0 \%$ and $33.3 \%)$ of nurses about definition of hypoalbuminemia and albumin is a major protein in human body were correct before teaching program respectively, compared with (96.7\% and $83.3 \%$ ) were correct after teaching program respectively with statistically significant differences $(\mathrm{P}<0.05)$. As regard albumin making up about $55-60 \%$ of total human plasma protein by mass, and the cause of hypoalbuminemia $(83.3 \%$ and 93.3\%) of nurses 'answers correctly before teaching program respectively, While the answers of them(93.3\% and $96.7 \%)$ were correct after teaching program respectively without statistically significant differences. Moreover, $(56.7 \%, 33.3 \%$ and $30.0 \%)$ of nurses' answers regarding hypoalbuminemia due to un adequate intake of amino acid, the signs and symptoms of hypoalbuminemia and Peripheral edema one of the most appearance symptoms of hypoalbuminemia were correct before teaching program respectively, While the answers of them (93.3\%, 90.0\% and 96.7\%) were correct after teaching program respectively with statistically significant differences $(\mathrm{P}<0.05)$.

This table also reveals that, the answer of $(66.7 \%$, $56.7 \%$ and $60.0 \%$ ) nurses correct regarding definition, indication and contraindication of liver transplantation before teaching program respectively, While the answers of them $(93.3,96.7$ and 90.0) were correct after teaching program respectively with statistically significant differences $(\mathrm{P}<0.05)$.

Table (3): present that the total scores of nurses' knowledge categories before and after teaching program. It was observed that there were statistical significant differences between nurses' knowledge categories indicating good knowledge after teaching program, Comparing with poor knowledge before teaching program.

Table (4): present that the total score of nurses' practice categories before and after teaching program. It was observed that there were statistical significant differences between nurses' practice categories indicating good practice after teaching program. Comparing with poor practice before teaching program.

Table (5): presents the correlation between total score of nurses' knowledge with practice before and after teaching program. There was no correlation between total score knowledge and practice of nurses before teaching program. While, a significant positive correlation was found between total score of nurses' knowledge and total practice after teaching program (r-value $=0.193$ and 0.785$)$ respectively.

\section{Discussion}

Hypoalbuminemia is a strong negative prognostic factor, being associated with a high mortality rate, high morbidity, and increased length of hospital stay. A large study involving patients from emergency departments revealed that hypoalbuminemia after liver transplantation increased the risk of mortality by three times in comparison to patients which had normal albumin levels. Practice nurses are a valuable 
resource for patients and specialist practitioners in the transplant center, as they tend to see patients on a more regular basis and may pick up earlier patient deterioration. (Gatta, 2012).

In the researcher opinion the teaching program for nursing staff constitute an important part. These programs are usually urgently designed to assist staff nurses in developing and enhancing the knowledge and practice needed to provide high standard of care to hypoalbuminemic patient after liver transplantation.

The research point of view, this lack of knowledge may be also due to absence of pre-employment orientation programs, in-service training program or courses about hypoalbuminemia after liver transplantation. Moreover, the nurses in the study are not used the independent self- learning. Another cause for lack of knowledge nurses` exhaustion due to increased workload which may be hinders their ability to read and update their knowledge.

The present study was done on 30 nurses who working in Intensive Care Unit at Alrajhy liver hospital. Near half of nurses $(53.3 \%)$ their age range from (25: >30) years, Most of them were females. Most of their work experiences are five or less, the larger part of nurses got a technical Institute of nursing with degree $(76.6 \%)$ and most of nurses had not trained about nursing care of hypoalbuminemia after liver transplantation. Also, Fayek, (2016) said that more than third of the nurses didn't have any previous data concerning hypoalbuminemia after liver transplantation, and generally every one of them were eager to the preparation program and expressed that they have the learning about hypoalbuminemia however the level of information was low among them.

Regarding the nurses' knowledge scores about anatomy and physiology of the liver, the present study documented that after implementation of teaching program it was noted that the majority of nurses show significant improvement in the nurse's knowledge about anatomy and physiology of the liver. This might be related to the fact that the larger part of nurses got a technical Institute of nursing and most of books are written in English and their learning in English. in this respect this finding agree with (Lee, 2011) who confirmed that the effectiveness of the teaching program in improving nurse's knowledge about anatomy and physiology of the liver and care of hypoalbuminemic patients after liver transplantation.

The current study figured out that, the level of knowledge of the majority of studied nurses generally was poor. This might be related to the fact that the technical nurses in the current study have lack of knowledge due to absence of pre-employment orientation programs, in-service training and courses. Moreover, the nurses in Egypt are not used the independent self-learning. Another cause for lack of knowledge nurses' exhaustion due to increased work load which may hinder their ability to read and update their knowledge. This result are in agreement with Martin (2014) that looked at the effect of an educational program on nursing staff with regard to nurse's knowledge about nursing care of patients with hypoalbuminemia after liver transplantation.

Regarding the nurses' practice scores about hypoalbuminemia after liver transplantation, the findings of the present study supported hypothesis (II), in which significant difference between post-test practice scores to the pretest practice scores following implementation of teaching program. The finding of the present study revealed that the majority of nurses didn't apply most of steps about caring for patient with hypoalbuminemia after liver transplantation, this could be attributing to the fact that this insufficient knowledge may be related to absence of pre-employment orientation, and inservice training programs. This result is in agreement with (Brock, 2016).

At last, it can be guessed that, the showing program for nurses caring for patients with hypoalbuminemia after liver transplantation has achieved its goals by enhancing nurse's practice and work on relating to care of patients with hypoalbuminemia after liver transplantation. This further was supported by (Schwartz, 2013); who stated that expert nurses have a large role to play in the care of patients with hypoalbuminemia after liver transplantation and must be complete of clinical practice.

As regarding, the relationship between knowledge and practice. The findings of this study supported the hypothesis III which stated that there will be a positive correlation between nurse's knowledge and performance scores. This reflects the importance of integration between theory and practice. In the same line, (Salgado, 2010) illustrated that nurses should maintain a high level of nursing knowledge and nursing practice but to be effective in practice, nurses must gain knowledge before they enter practice.

\section{Conclusion}

Based on results of this study, it can be figure out that:

- A statistical significant improvement was found between the critical care nurses' performance immediately after application of teaching program related to hypoalbuminemia after liver transplantation. 


\section{Recommendations}

In light of the findings of the present study

- Continuous nursing instruction and in benefit preparing programs in intensive care unit ought to be efficient at Alrajhy liver hospital at Assuit university.

- All nurses should take regular training about hyboalbuminemia after liver transplantation.

- All the nurses should be furnished with the basic knowledge and practice to deal with hypoalbuminemic patients in Intensive Care Unit at Alrajhy liver hospital.

- The manual procedure should be available to allow nurses' to act in true manner during dealing with patient.

\section{References}

1. Jewell T., (2017): What is hypoalbuminemia and how is it treated? Medically reviewed by Carissa Stephens, RN, CCRN, CPN on August 10, 2017.P 1-3.

2. Peralta R., (2017): Hypoalbuminemia Clinical Presentation. P 1\3.

3. Fullwood D., Jones F., Lau-walker M., (2011): Care of patients following liver transplantation. Nursing standard. 25, 49, 50-56.

4. Karaahmet F., Coban S., Yuksel I., (2014): Gastrointestinal bleeding and transfusion strategies in patients with hypoalbuminemia.

5. Dultz G., Graubard B., Martin P., Welker M., Vermehren J., Zeuzem S., Mcglynn K., Welzel T., (2017): Liver transplantation for chronic hepatitis $\mathrm{C}$ virus infection in the United States.

6. Brodovicz K., McNaughton K., Uemura N., Meininger G., Girman C., Yale S., (2010): Reliability and feasibility of methods to quantitatively assess peripheral edema. Clinical Medicine \& Research, 7(1/2) P 21-31.

7. Hogan, M., (2014). Medical Surgical nursing (2nd ed). Salt Lake City: Prentice Hall.

8. Cheng H., Chang W., Chen W., Kao A., Chuang C., Sheu B., (2013): Intravenous albumin shortens the duration of hospitalization for patients with hypoalbuminemia and bleeding peptic ulcers: a pilot study. Dig Dis Sci. 58:3232-3241.

9. Gatta A., Verardo A., Bolognesi M., (2012): Hypoalbuminemia. Intern Emergency Med. 7 Suppl 3: S193-9.

10. Fayek S., Quintini C., Chavin K., Marsh C., (2016): The Current State of Liver Transplantation in the United States: 16:30933104.
11. Lee W., Larson A., Stravitz R., (2011): AASLD Position Paper: The Management of Acute Liver Failure: Update 2011. American Association for the Study of Liver Diseases.

12. Martin P., DiMartini A., Feng S., Brown R., J., Fallon M., (2014): Practice guideline by the American Association for the Study of Liver Diseases and the American Society of Transplantation. 59:1144-65.

13. Brock F., Bettinelli L., Dobner T., Stobbe J., Pomatti G., Telles C., (2016): Prevalence of hypoalbuminemia and nutritional issues in hospitalized elders.

14. Schwartz J., Winters J., Padmanabhan A., Balogun R., Delaney M., Linenberger M., Jeffrey L., Rasheed A., Michael L., Zbigniew M., Szczepiorkowski, Mark E., Williams, Yanyun W., Beth H., (2013): Guidelines on the use of therapeutic apheresis in clinical practiceevidence-based approach from the Writing Committee of the American Society for Apheresis: the sixth special issue. J Clin Apher. 145-284.

15. Salgado F., Vianna L., Giavoni A., Melo G., Karnikowski M., (2010): Hypoalbuminemia terapia medicamentosa no prognóstic odeidosos hospitalizados. Rev Assoc Méd Bras. 56(2):14550.1 . 